\title{
Cerebral Accumulation of Dietary Derivable Plant Sterols does not Interfere with Memory and Anxiety Related Behavior in Abcg5-/- Mice
}

\author{
Tim Vanmierlo • Kris Rutten - Leonie C. van Vark - van der Zee • Silvia Friedrichs • \\ Vincent W. Bloks • Arjan Blokland • Frans C. Ramaekers • Eric Sijbrands • \\ Harry Steinbusch • Jos Prickaerts • Folkert Kuipers • Dieter Lütjohann • \\ Monique Mulder
}

Published online: 24 March 2011

(C) The Author(s) 2011. This article is published with open access at Springerlink.com

\begin{abstract}
Plant sterols such as sitosterol and campesterol are frequently applied as functional food in the prevention of atherosclerosis. Recently, it became clear that plasma derived plant sterols accumulate in murine brains. We questioned whether plant sterols in the brain are associated
\end{abstract}

T. Vanmierlo $\cdot$ K. Rutten $\cdot$ H. Steinbusch $\cdot$ J. Prickaerts $\cdot$

M. Mulder

Department of Neuroscience, Maastricht University,

Universiteitssingel 50,

6229 ER Maastricht, The Netherlands

T. Vanmierlo $\cdot$ S. Friedrichs $\cdot$ D. Lütjohann

Institute of Clinical Chemistry and Clinical Pharmacology,

University Clinics Bonn,

Sigmund-Freud-Str. 25,

53105 Bonn, Germany

L. C. van Vark - van der Zee $\cdot$ E. Sijbrands $\cdot$ M. Mulder $(\square)$ Department of Internal Medicine, Division of Pharmacology, Vascular and Metabolic Diseases, Erasmus Medical Center,

's-Gravendijkwal 230,

3015 CE Rotterdam, The Netherlands

e-mail: m.t.mulder@erasmusmc.nl

V. W. Bloks $\cdot$ F. Kuipers

Department of Pediatrics, University Medical Center Groningen, Hanzeplein 1,

9713 GZ Groningen, The Netherlands

\section{A. Blokland}

Department of Neuropsychology and Psychopharmacology,

Maastricht University,

Universiteitssingel 40,

6229 ER Maastricht, The Netherlands

F. C. Ramaekers

Department of Molecular Cell Biology, Maastricht University,

Universiteitssingel 50,

6229 ER Maastricht, The Netherlands with alterations in brain cholesterol homeostasis and subsequently with brain functions. ATP binding cassette (Abc)g5-/- mice, a phytosterolemia model, were compared to Abcg $5+/+$ mice for serum and brain plant sterol accumulation and behavioral and cognitive performance. Serum and brain plant sterol concentrations were respectively 35-70-fold and 5-12-fold increased in Abcg5-/mice $(P<0.001)$. Plant sterol accumulation resulted in decreased levels of desmosterol $(P<0.01)$ and 24(S)hydroxycholesterol $(P<0.01)$ in the hippocampus, the brain region important for learning and memory functions, and increased lanosterol levels $(P<0.01)$ in the cortex. However, Abcg5-/- and Abcg5+/+ displayed no differences in memory functions or in anxiety and mood related behavior. The swimming speed of the Abcg5-/- mice was slightly higher compared to Abcg5+/+ mice $(P<0.001)$. In conclusion, plant sterols in the brains of Abcg5-/- mice did have consequences for brain cholesterol metabolism, but did not lead to an overt phenotype of memory or anxiety related behavior. Thus, our data provide no contra-indication for nutritional intake of plant sterol enriched nutrition.

Keywords Abcg5 · Anxiety · Cholesterol - Cognition . Phytosterolemia and plant sterol

$\begin{array}{ll}\text { Abbreviations } \\ \text { ABC } & \text { ATP binding cassette } \\ \text { BBB } & \text { blood-brain barrier } \\ \text { CVD } & \text { cardiovascular diseases } \\ \text { DM } & \text { distance moved } \\ \text { EZM } & \text { elevated zero maze } \\ \text { LDL } & \text { low density lipoprotein } \\ \text { LXR } & \text { liver x receptor }\end{array}$

Abbreviations

ABC ATP binding cassette

blood-brain barrier

cardiovascular diseases

distance moved

EZM elevated zero maze

LXR liver $\mathrm{x}$ receptor 
MWEM Morris water escape maze

OF open field

ORT object recognition task

TIZ time in zone

TST tail suspension task

\section{Introduction}

Consumption of high amounts of plant sterols leads to reduced serum and LDL cholesterol concentrations, making them attractive compounds in the treatment of atherosclerosis and cardiovascular diseases (CVD) [1]. Besides their natural presence in the diet [2], plant sterols are frequently administered as functional food additives in the prevention of atherosclerosis, although no hard endpoint studies are available [3]. Plant sterols, exclusively derived from the diet, differ from cholesterol only by an additional ethyl or methyl group at $\mathrm{C} 24$ and/or a double bond at C22 [4]. Cholesterol in the circulation is prevented from entering the brain by the blood-brain barrier (BBB), and all cholesterol within the brain is synthesized in situ. Unlike dietary cholesterol, plant sterols can accumulate in the brain [5].

ATP binding cassette (ABC)G5 and ABCG8 act as functional heterodimer transporters at the apical membranes of enterocytes and hepatocytes where they resecrete plant sterols into the intestinal lumen and bile, respectively. Despite this exclusion mechanism, small amounts of plant sterols reach the brain. In humans and mice defects in ABCG5 and/or ABCG8 cause phytosterolemia, a rare autosomal recessive disorder characterized by a massive plant sterol accumulation in the circulation and tissues [6]. Patients with phytosterolemia display xanthoma, an increased risk of premature atherosclerosis, hemolysis, and macrothrombocytopenia [7, 8].

Brain cholesterol homeostasis is a complex but well orchestrated system featured by important synthesis intermediates (e.g., lanosterol, desmosterol and lathosterol) and the brain specific metabolite 24(S)-OHcholesterol [9]. Disturbances herein are associated with severe neurological diseases, such as Smith-Lemli-Opitz's syndrome [10]. Within the brain plant sterols may alter cholesterol metabolism by enhancing cholesterol turnover via activation of Liver X receptors (LXRs) [11]. In line with an involvement of brain cholesterol metabolism in memory processes [12], we recently reported brain cholesterol turnover to be associated with enhanced memory functions and in a model of Alzheimer's disease by LXR-activation [13].

Although, circulating cholesterol is assumed not to accumulate in the brain, patients with depression, anxiety, co-morbid depression, suicidal ideation and current or past suicidal behavior display low serum cholesterol levels $(<160 \mathrm{mg} / \mathrm{dl})$ (for review, see: [14]). Moreover, monkeys fed a low cholesterol diet exhibited less affiliative interaction in comparison with their counterparts fed a normal diet [15]. In vitro decreased neuronal membrane cholesterol concentrations were found to reduce serotonin neurotransmission which may be involved in the underlying mechanisms [16]. Notably, phytosterolemia patients, which are rare $( \pm 100$ known cases worldwide), are relatively highly educated (personal communication Dr. G. Salen) and cognitive performance in healthy subjects was positively correlated with a high fruit and vegetable intake, suggestive of potential beneficial effects of high plant sterol concentrations. Therefore, we addressed the question whether accumulation of plant sterols in the brain interferes with brain cholesterol homeostasis and if this consequently affects memory, mood, and anxiety related behavior.

\section{Materials and Methods}

\section{Animals}

Male Abcg5-/- mice $(n=8)$ and Abcg5+/+ littermates $(n=9)$, generated on a mixed C57BL/6Jx129/OlaHsd background by Deltagen (Redwood City, CA, USA) as described by Plösch et al. [17] were fed a standard laboratory chow diet. Animals had ad libitum access to the diet and water. Mice were subjected to behavioral tasks on an adult age between 7 and 9 months, conform with previous descriptions [18]. The sequence of behavioral tasks was set to perform the least stressful tasks first. Experimental procedures were approved by the local ethical committee of Maastricht University.

\section{Object Recognition Task}

The object recognition task (ORT) was performed as described previously $[18,19]$ with following specifications. Following two habituation days, mice were subjected to a first trial $(\operatorname{Tr} 1)$ in which the arena contained two identical objects. After 4 min exploration, the mouse was placed back into its home cage. $1 \mathrm{~h}$ later, the mouse was returned to the arena for the second trial of $4 \min (\operatorname{Tr} 2)$, now with two dissimilar objects: the familiar object and a new object. The discrimination index $\mathrm{d} 2$ in $\operatorname{Tr} 2$ was calculated as measure for object memory $(\mathrm{d} 2=[$ (exploration time for the novel object in $\operatorname{Tr} 2$ ) - (exploration time for the familiar object in $\operatorname{Tr} 2)] /[$ total exploration time in $\operatorname{Tr} 2]$ ).

\section{The Morris Water Escape Maze}

Spatial memory performance was measured in the Morris water escape maze (MWEM) as described previously [20]. 
In brief, the mice were subjected to a total of 24 acquisition trials: 6 days, 4 trials a day, separated by a 5 min inter-trial interval, using 4 different starting positions assigned in a random order between mice to avoid side bias. A gray platform (diameter $5 \mathrm{~cm}$ ), submerged beneath the water surface, was located at one fixed position for all mice throughout the experiments. Acquisition time (s), distance moved (cm), and swimming speed $(\mathrm{cm} / \mathrm{s})$ were measured (Etho Vision ${ }^{\mathrm{TM}}$, Noldus, Wageningen, The Netherlands). $1 \mathrm{~h}$ after the final acquisition trial (day 6), mice were subjected to a probe trial in which the platform was removed from the pool. Mice were released into the pool, opposite to the previous platform location and allowed to search for the platform over a period of $60 \mathrm{~s}$. The arena was divided into four quadrants, with the target zone being the quadrant where the platform was previously located.

\section{Elevated Zero Maze}

The elevated zero maze (EZM), originally described in Shepherd et al., was made of black, infrared-transparent, plastic [21]. It consists of a circular runway $(50 \mathrm{~cm}$ in diameter), $6 \mathrm{~cm}$ path width, $20 \mathrm{~cm}$ above floor level) which was divided equally into two opposite open zones (OZ) and two opposite zones, enclosed with $20 \mathrm{~cm}$ high side walls (CZ) [22]. Measurements were performed under almost dark conditions for the open area (1-2lux). The entrance of each $\mathrm{OZ}$ and $\mathrm{CZ}$ contains at each side respectively two outer border (BO) and two inner border (BI) areas, covering $3 \mathrm{~cm}$ of the running way each. A $3 \mathrm{~mm}$ high edge surrounded the open zones to prevent falls. Time spent and distance moved in $\mathrm{OZ}, \mathrm{BI}, \mathrm{BO}$, and $\mathrm{CZ}$ during a 5 min trial were measured via an infrared video camera connected to a video tracking system (Etho Vision ${ }^{\mathrm{TM}}$, Noldus, Wageningen, The Netherlands).

\section{Tail Suspension Task}

The tail suspension task (TST) is designed to test antidepressant-like activity in mice [23]. The test is based on the fact that animals subjected to the short-term, inescapable stress of being suspended by their tail, will develop an immobile posture [24]. Four cages with closed side walls and an open front were used to test the mice in the TST (18 cm of width and $30 \mathrm{~cm}$ of height). Each animal was individually hung by its tail to a hook at the ceiling of the chamber, using adhesive tape. Their movements were recorded for $5 \mathrm{~min}$ using a video camera device (Etho Vision ${ }^{\mathrm{TM}}$, Noldus, Wageningen, The Netherlands). The behavioral variable "immobility" was defined as no movement or no obvious effort to escape from the hook (cutoff: $15 \%$ movement). Total activity versus inactivity is regarded as a measure of antidepressant-like activity of plant sterols.

\section{Open Field}

The open field test (OF) was conducted over 20 min as described previously [12]. After a mouse was placed in the centre of the OF, the distance moved (DM) and time spent in each zone (TIZ) were registered (Etho Vision ${ }^{\mathrm{TM}}$, Noldus, Wageningen, The Netherlands).

\section{Sterol Profile Determination}

Following the behavioral experiments, mice were anaesthetized with IP ketamine/xylazine $(100 \mathrm{mg} / \mathrm{kg}$ ketamine and $5 \mathrm{mg} / \mathrm{kg}$ xylazine). Blood was collected prior to perfusion with ice cold PBS by puncturing the right atrium of the heart. Prior to the sterol analysis the cerebellum, right hippocampus and top part of the neo-cortex (Bregma $-0.5 \mathrm{~mm}$ to $-4 \mathrm{~mm}$ ) were dissected out and snap frozen.

Samples were spun in a speedvac (12 mbar) (Savant AES 1000 ) for $24 \mathrm{~h}$ in order to relate individual sterol concentrations to dry weight. Cholesterol and non-cholesterol sterol concentrations were extracted and quantified by respectively gas-chromatography-FID and gas-chromatography/mass spectrometry as described previously [25].

\section{Statistics}

All statistical analyses were performed using GraphPad Prism $4^{\mathrm{TM}}$. Acquisition times, distance covered and speed in the MWEM were analyzed using the two-way ANOVA. The MWEM probe trial, the OF locations and between region brain sterols were analyzed by one-way ANOVA with a post hoc Bonferroni's multiple comparison test (indicated as "PH"). An unpaired two-sided Student's $t$-test was applied to compare the genotypes in the ORT, OF and sterol (between groups) analyses. d2 values (ORT) were compared to 0 by a one sample Student's $t$-test. Animals not reaching the minimum of $5 \mathrm{~s}$ exploration in ORT were excluded from analysis [19]. Extreme values were excluded by means of Dixon's principles of exclusion of extreme values.

\section{Results}

Cerebral Sterol Metabolism in ABCG5-/and ABCG5+/+ mice

Corroborating previous results $[5,17]$, Abcg5-/- mice on normal chow diet displayed strongly increased serum concentrations of sitosterol, campesterol, and stigmasterol 
(30-, 5- and 70-fold, respectively) in comparison with their wild-type littermates, whereas cholesterol concentrations were significantly decreased (2-fold) (data not shown).

All brain regions of the Abcg5-/- mice, displayed higher concentrations of sitosterol (12-fold), campesterol (7-fold), and stigmasterol (5-fold) than those of Abcg5+/+ mice (Table 1). Both Abcg5+/+ and Abcg5-/mice display the highest absolute concentrations of sitosterol $(P<0.01)$ and campesterol $(P<0.01)$ in the cerebellum in comparison with the cortex and the hippocampus (Table 1). Also the ratio of sitosterol and campesterol over cholesterol was highest in the cerebellum in Abcg5-/- mice, but not in Abcg5+/+ mice. No regional absolute or relative differences were found for stigmasterol in Abcg5-/- group. Thus, Abcg5-/- mice on a normal laboratory chow diet were prone to accumulate plant sterols in their brain, in particular in the cerebellum. In Abcg5-/- mice, plant sterol concentrations in the brain were not directly related to their serum concentrations. Abcg5-/- mice displayed serum sitosterol concentrations that were twice as high as campesterol (data not shown), while campesterol concentrations were higher in the brain. Despite overall increases in brain plant sterol concentrations, the concentrations of endogenous sterols were affected to a limited extent only in specific brain regions (Table 1), particularly in the hippocampus. Lanosterol concentrations were increased in the cortex of Abcg $5-/-$ mice $(P<0.01)$ and to a lesser extent also in the hippocampus, in line with increased concentrations in serum $(P<0.001)$. Desmosterol $(P<0.01)$ and
24(S)-OHcholesterol $(P<0.01)$ concentrations were significantly reduced (to $72 \%$ and $68 \%$ of the control levels, respectively) exclusively in the hippocampus.

Learning and Memory Functions in Abcg5-/and Abcg5+/+ Mice

Abcg5-/- and Abcg5+/+ mice displayed no detectable differences in general behavior. To examine possible effects of elevated brain plant sterols on learning and memory functions, Abcg5-/- and Abcg5+/+ littermates were subjected to the ORT and MWEM.

$\mathrm{d} 2$ values were significantly higher than 0 for both the Abcg5-/- $(P<0.01)$ and Abcg5+/+ mice $(P<0.01)$, indicating good memory performance (Fig. 1). Exploration times were comparable (data not shown), whereas the $\mathrm{d} 2$ values for Abcg5-/- mice were slightly, but not significantly $(P=0.28)$ higher in comparison with the Abcg $5+/+$ mice (Fig. 1). Hence, increased plant sterol levels in the brain of the Abcg5-/- mice did not result in detectable influences on object memory performance at the $1 \mathrm{~h}$ intertrial interval.

Subsequently, both groups were subjected to MWEM. Both the Abcg5-/- and the Abcg5+/+ mice located the platform well (acquisition time: $F(5,90)=31.58 ; P<0.001$ (Fig. 2a) and acquisition distance: $(F(5,90)=22.02 ; P<$ 0.001 ; data not shown), but there were no significant differences in the acquisition times and distances covered to reach the platform at the different experimental days between the two groups. At day $6,1 \mathrm{~h}$ after the last
Table 1 Sterol profiles in brain regions of Abcg5-/- and Abcg5+/+ mice on normal chow diet
$H C$ hippocampus, $C T X$ cortex, and $C B$ cerebellum. Abcg5+/+ $(n=7)$ Abcg5+/+ $(n=8)$, mean \pm SEM.

$*=$ Between group 2 sided unpaired Student's $t$-test; \# = ANOVA within group Bonferroni post hoc: HC/CTX vs $\mathrm{CB} ; \S=$ ANOVA within group Bonferroni post hoc: $\mathrm{HC}$ vs CTX. * $, \S, \#=P<0.05 ; * *, \S \S$,

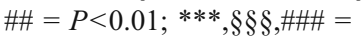
$P<0.001$

\begin{tabular}{|c|c|c|c|c|}
\hline Brain & Abcg5 & $\mathrm{HC}$ & CTX & $\mathrm{CB}$ \\
\hline \multirow[t]{2}{*}{ Cholesterol ( $\mu \mathrm{g} / \mathrm{mg})$} & $+/+$ & $71.5(3.4) \#$ & 61.3 (3.4) \#\#\# & $91.2(3.6)$ \\
\hline & $-1-$ & 66.8 (5.9) \#\# & 63.3 (4.2) \#\# & $89.0(3.6)$ \\
\hline \multirow[t]{2}{*}{ Sitosterol (ng/mg) } & $+/+$ & $35.6(6.2) * * * \# \#$ & $32.2(3.7) * * * \# \#$ & $61.4(7.4) * * *$ \\
\hline & $-1-$ & 422.9 (71.0) \#\# & 381.1 (44.3) \#\# & $772.7(91.2)$ \\
\hline \multirow[t]{2}{*}{ Campesterol (ng/mg) } & $+/+$ & $71.3(10.6) * * *$ \#\# & 60.9 (7.4) *** \#\# & $143.6(26.7) * * *$ \\
\hline & $-1-$ & $504.2(82.1) \# \#$ & 465.9 (54.3) \#\# & $947.6(109.0)$ \\
\hline \multirow[t]{2}{*}{ Stigmasterol (ng/mg) } & $+/+$ & $3.7(0.7) * * * \# \# \#$ & $4.2(0.5)$ *** \#\# & $8.4(0.9) * * *$ \\
\hline & $-1-$ & $25.5(3.8)$ & $23.9(2.1)$ & $34.4(2.6)$ \\
\hline \multirow[t]{2}{*}{ Lathosterol (ng/mg) } & $+/+$ & $68.6(3.3)$ & $70.0(2.1)$ & $78.2(5.8)$ \\
\hline & $-1-$ & $83.1(18.4)$ & $88.6(9.0)$ & $87.7(5.9)$ \\
\hline \multirow[t]{2}{*}{ Desmosterol (ng/mg) } & $+/+$ & $422.0(14.6) * * \S \S \S$ & 277.9 (9.0) \#\#\# & $406.6(30.2)$ \\
\hline & $-1-$ & $305.8(28.6) \#$ & $312.1(19.7)$ & $400.8(25.4)$ \\
\hline \multirow[t]{2}{*}{ Lanosterol (ng/mg) } & $+/+$ & $13.0(2.0)$ & $12.8(0.6) * *$ & $17.8(1.0)$ \\
\hline & $-1-$ & $16.1(2.8)$ & $17.1(1.1)$ & $17.0(2.2)$ \\
\hline \multirow[t]{2}{*}{ 27-OHchol (ng/mg) } & $+/+$ & $6.1(2.0) \S$ & $1.1(0.2)$ & $2.7(0.5)$ \\
\hline & $-1-$ & 6.7 (1.3) $\S \S \S \# \#$ & $1.0(0.16)$ & $2.4(0.2)$ \\
\hline \multirow[t]{2}{*}{ 24-OHchol (ng/mg) } & $+/+$ & $300.7(20.0) * * \S \# \# \#$ & 244.3 (11.4) \#\#\# & $56.6(4.3)$ \\
\hline & $-1-$ & $205.8(16.5) \S \# \# \#$ & 266.6 (8.5) \#\#\# & $48.3(3.3)$ \\
\hline
\end{tabular}




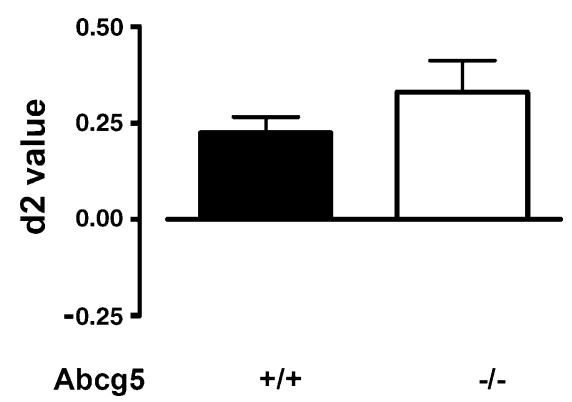

Fig. 1 The performance of Abcg5-/- compared to Abcg5+/+ mice in the ORT. The Abcg5 genotype had no influence on object memory performance in an ORT with a $1 \mathrm{~h}$ delay between $\operatorname{Tr} 1$ and $\operatorname{Tr} 2$. Animals that did not reach the minimum of $5 \mathrm{~s}$ exploration in ORT in either $\operatorname{Tr} 1$ or $\operatorname{Tr} 2$ were excluded from $\mathrm{d} 2$ analysis (exclusion numbers: Abcg5-/- $(n=1)$ and Abcg5+/+ $(n=1))$ (Sik et al. 2003). Extreme values were excluded by means of Dixon's principles of exclusion of extreme values (exclusion numbers: Abcg5-/- $(n=0)$ and Abcg5+/+ $(n=1 ; \mathrm{d} 2=0.60))$. No differences in $\mathrm{d} 2$ values could be detected between Abcg5-/- $(n=7)$ and Abcg5+/+ $(n=7)(\mathrm{a}) . \mathrm{T} 1(\mathrm{~s})$ and T2(s) exploration times in respectively $\operatorname{Tr} 1$ and $\operatorname{Tr} 2$ were not different between Abcg5-/- $(n=8)$ and Abcg5 $+/+(n=9)$ (data not shown). Values are displayed as mean $+/-$ SEM

acquisition trial, a $1 \mathrm{~h}$ probe trial was performed. Both genotypes spent significantly more time in the target quadrant compared to the other quadrants indicating both groups memorized the prior location of the platform (Fig. 2c). However, since no differences between the two groups were detected, it can be concluded that neither object- nor spatial memory was significantly affected by increased brain plant sterol concentrations. Remarkably, Abcg5-/- $(15.03 \pm 1.07 \mathrm{~cm} / \mathrm{s})$ displayed a significantly higher swimming speed than their wild-type littermates $(12.87 \pm 0.88 \mathrm{~cm} / \mathrm{s})(F(1,90)=13.49 ; P<0.001$, Fig. $2 \mathrm{~b})$.

Performance of Abcg5-/- and Abcg5+/+ in the EZM, TST and OF

In order to examine the effects of plant sterol accumulation on anxiety- and mood- related behavior, mice were subjected to the elevated zero maze (EZM), tail suspension task (TST), and the open field (OF).

In the EZM, a model for anxiety in rodents, the latency of first entrance of the closed zone $(P=0.35)$, time spent in the closed zone $(P=0.24)$, open zone $(P=0.71)$, inner borders $(P=0.66)$ and outer borders $(P=0.52)$ as well as the frequency of entrances did not significantly differ between Abcg5-/- and Abcg5+/+ mice (Fig. 3a-c). Furthermore, the TST did not reveal differences in depression related behavior, measured by immobility $(P=0.37$; Fig. $3 \mathrm{~d})$. In the OF task both Abcg5-/- $(F(2,20)=14.65 ; P<0.001)$ and Abcg5 $+/+(F(2,26)=50.14 ; P<0.001)$ mice spent most of their time in the corners and near the walls, whereas the center of the arena was avoided (data not shown). No significant differences were detected between the Abcg5-/- and Abcg5 $5+/+$ mice with respect to the time spent in the center $(P=0.14)$, the corners $(P=0.54)$, or near the walls ( $P=$ $0.19)$. Although, there was a difference in swimming speed in MWEM, the locomotor activity in the OF task was comparable between the two groups (Abcg5+/+: $8.8 \pm 1.2 \mathrm{~m}$ versus Abcg5-/-: $7.1 \pm 0.5 \mathrm{~m}$ ).

\section{Discussion}

Plant sterols are massively applied as functional nutrition in the prevention of atherosclerosis. It has become clear that plant sterols can accumulate in the brain. Therefore, our observations that accumulation of plant sterols in the brain to a limited extend affected brain cholesterol metabolism, but did not have major effects on memory functions or on anxiety and mood related behavior in Abcg5-/- mice in the applied tasks are of major importance. The Abcg5-/- mice did display an increased swimming speed in the MWEM.

As previously reported, in the absence of the Abcg 5 gene, plant sterols accumulated not only in serum, but also in the brain [5]. In addition to Plösch et al. [17] and Jansen et al. [5] who report increased plant sterol levels in serum and total brain hemispheres homogenates respectively, we now demonstrate that campesterol and sitosterol, relative to the local cholesterol content, accumulate predominantly in the
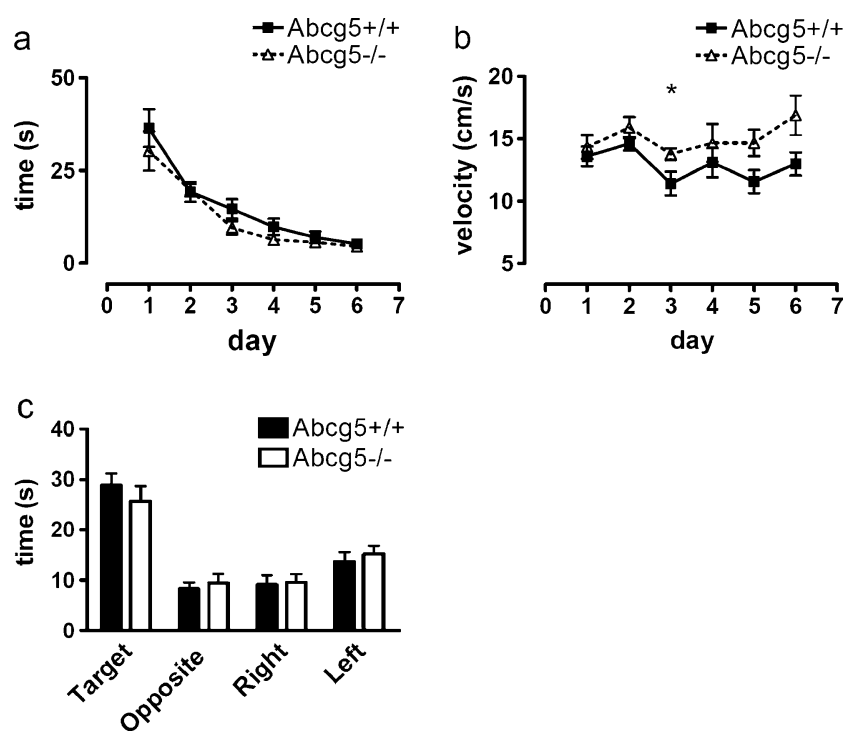

Fig. 2 Spatial learning and memory of Abcg5-/- compared to Abcg $5+/+$ mice in the MWEM. Spatial memory performance did not differ between Abcg5+/+ and Abcg5-/- mice in the MWEM. Acquisition times (a) and distance moved were not different between the Abcg5+/+ $(n=9)$ and Abcg5-/- $(n=8)$. Abcg5-/- mice swam significantly faster than the Abcg5+/+ mice (b). In a probe trial without platform, all mice spent significantly more time searching in the target zone and no differences were found between Abcg5+/+ and Abcg5-/mice (c). Using software the pool was divided into 4 virtual quadrants and a target zone. Values are displayed as mean $+/-$ SEM, $*=P<0.05$ 

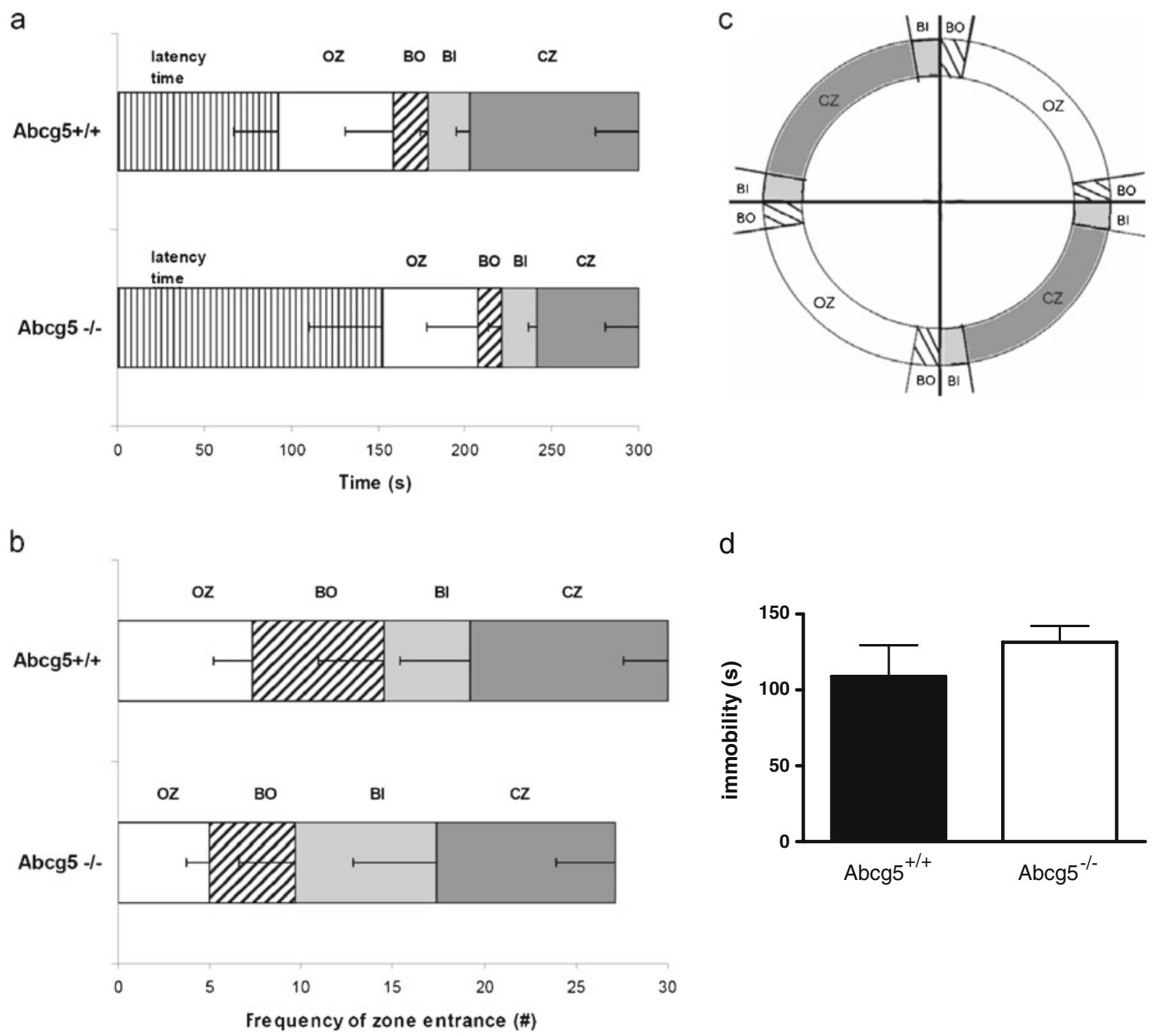

d

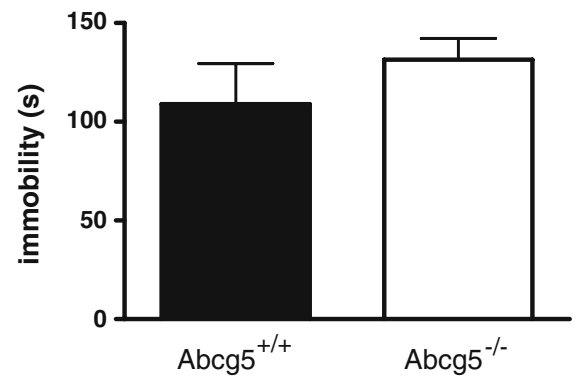

Fig. 3 Behavior of the Abcg5-/- and the Abcg5+/+ mice in the EZM and TST. Mice were allowed to explore the EZM for $5 \mathrm{~min}$. The time in zone in the open zone $(\mathrm{OZ})$, the closed parts $(\mathrm{CZ})$, the border-in (BI), the border-out (BO) (indicated in (c)) as well as the latency to

cerebellum of the Abcg5-/- mice. However, the high plant sterol concentrations in the brain were associated with increased changes in cholesterol metabolism particularly in the hippocampus. Lanosterol concentrations were increased in the cortex, and desmosterol- and 24(S)-OHcholesterol concentrations were decreased in the hippocampus. Since we previously found no significant differences in the expression of genes involved in the brain cholesterol homeostasis of Abcg5-/- versus Abcg5+/+ mice on normal chow [5], we examined gene expression in the brains of Abcg5+/+ $(n=6)$ and Abcg5-/- $(n=3)$ mice, further challenged with a high plant sterol diet for a period of three months (data not shown). The expression of the LXR target genes Abcal $(P<0.05)$ and Abcg1 $(P<0.05)$ were significantly increased in the hippocampus of Abcg5-/mice in comparison to Abcg5+/+ mice on a high plant sterol diet. However, other LXR responsive genes, Srebp1c, enter the $\mathrm{CZ}$ (latency) did not differ between Abcg5+/+ and Abcg5-/mice in the EZM (a). The frequency of entrance in CZ, OZ, BO and BI were not significantly different either $(\mathbf{b})$. Immobility times in the TST are displayed as mean $+/-$ SEM

Apoe, ApocI and LXR $\alpha$ which are known to be significantly upregulated by the synthetic LXR-activator T0901317 [13] remained unaffected (data not shown), suggesting the mechanism for their upregulation is not via the LXRpathway. Together, these data indicate that elevated plant sterol concentrations in the brain modestly affect cholesterol metabolism in a brain region specific manner, with the strongest effect in the hippocampus.

Our data show that despite the substantially increased brain plant sterol concentrations in the Abcg5-/- mice, neither spatial nor object memory were significantly affected, showing no overt negative influences of plant sterols. In the present study, the ORT was performed using a $1 \mathrm{~h}$ inter-trial interval in order to reveal a strong overt phenotype. However, both groups approached ceiling d2 values in the ORT, indicating hardly improvable memory [19]. In parallel to a T0901317 treated Alzheimer mice 
showing improved memory in the ORT, whereas control littermates remained on ceiling levels after T0901317 administration, a beneficial role for plant sterols on memory in neurodegenerative diseases cannot be excluded. In line herewith, patients with familial hypercholesterolemia (FH) on statin therapy in combination with plant sterol supplementation displayed a higher incidence of mild cognitive impairment [26]. In contrast, a recent study showed that 85 weeks of dietary plant sterol supplementation of 4369 year old statin-treated hypercholesterolemic individuals did not affect cognitive functions [27]. Yet, both studies, however, did not take possible effects of statins on cognition into account [28, 29]. In another study, no correlation between serum sitosterol and campesterol concentrations and cognitive performance in a healthy aging population could be detected, neither at baseline nor after 6 years of follow-up [30]. Although Abcg5-/- mice differ at some points from FH and phytosterolemic patients; e.g. Abcg5-/- mice do not develop premature atherosclerosis [31], they provide a good model to study functional consequences of brain plant sterol accumulation by bearing high serum plant sterol concentrations comparable to $\mathrm{FH}$ and phytosterolemic patients.

Although no differences in running speed were recorded in the unforced movement tasks such as the OF and EZM, Abcg5-/- mice displayed a significantly increased swimming speed during the acquisition trials in the MWEM compared with their Abcg5+/+ littermates. However, in contrast, administering extracts of the plant species Leucas inflata Labiatae, containing high concentrations of stigmasterol, significantly reduced performance on a rotarod assay in mice [32]. Therefore, plant sterols might influence other, none CNS related parameters in the MWEM, e.g., thermoregulation, which can affect swimming speed outcome [33].

Decreased serum cholesterol concentrations have been associated with severe depressive behavior [14]. However, the markedly suppressed serum cholesterol concentrations caused by elevated serum plant sterol concentrations in the Abcg5-/- mice did not affect anxiety and mood related behavior as indicated by their performance in the applied tasks. Plant sterols from the plant species, Tilia americana var. mexicana, have been reported to possess anxiolitic properties, with sitosterol as the identified bioactive anxiolytic compound, having a dose dependent sedative response resembling diazepam [34]. Nonetheless, the strongly increased serum and brain sitosterol concentrations in the Abcg5-/- mice were not associated with aberrant behavior in anxiety or mood related tasks. Therefore, our results show no overt effects of strongly elevated brain plant sterol levels on unforced mood or anxiety related behavior in mice. Further studies (e.g., conditioned anxiety tests) may elucidate if other cognitive and emotive domains are similarly unaffected.
Since high concentrations of plant sterols $(2.25 \mathrm{~g} /$ day $)$ are advised without prescriptions as functional food in the prevention of atherosclerosis, it is of major importance that we demonstrate that even strongly elevated serum and brain plant sterol concentrations in a phytosterolemia mouse model, Abcg5-/- mice, did not result in an overt phenotype in behavioror, e.g., memory, anxiety and mood in the applied behavioral tasks. Therefore, this study does not provide a contra-indication for nutritional intake of plant sterol enriched nutrition.

Acknowledgements We are grateful to Professor Dr. Gerald Salen and Dr. Patric Delhanty for critically reading the manuscript. We would like to thank Juul Baller for his excellent technical assistance. The project was financially supported by Marie Curie Early Stage Training Fellowship: Contract number MEST-CT-2005-02058. All experimental procedures concerning the used mice were approved by the local ethical committee of the Maastricht University for animal experiments according to governmental guidelines.

Conflicts of Interest There are no actual conflicts of interest.

Open Access This article is distributed under the terms of the Creative Commons Attribution Noncommercial License which permits any noncommercial use, distribution, and reproduction in any medium, provided the original author(s) and source are credited.

\section{References}

1. Thompson GR, Grundy SM (2005) History and development of plant sterol and stanol esters for cholesterol-lowering purposes. Am J Cardiol 96:3D-9D

2. Ryan E, Galvin K, O'Connor TP, Maguire AR, O'Brien NM (2007) Phytosterol, squalene, tocopherol content and fatty acid profile of selected seeds, grains, and legumes. Plant Foods Hum Nutr 62:85-91

3. Clifton P (2009) Lowering cholesterol - a review on the role of plant sterols. Aust Fam Physician 38:218-221

4. Salen G, Ahrens EH Jr, Grundy SM (1970) Metabolism of beta-sitosterol in man. J Clin Invest 49:952-967

5. Jansen PJ, Lutjohann D, Abildayeva K, Vanmierlo T, Plosch T, Plat J, von Bergmann K, Groen AK, Ramaekers FCS, Kuipers F, Mulder M (2006) Dietary plant sterols accumulate in the brain. Biochim Biophys Acta 1761:445-453

6. Berge KE, Tian H, Graf GA, Yu L, Grishin NV, Schultz J, Kwiterovich P, Shan B, Barnes R, Hobbs HH (2000) Accumulation of dietary cholesterol in sitosterolemia caused by mutations in adjacent ABC transporters. Science 290:1771-1775

7. Kruit JK, Drayer AL, Bloks VW, Blom N, Olthof SG, Sauer PJ, de Haan G, Kema IP, Vellenga E, Kuipers F (2008) Plant sterols cause macrothrombocytopenia in a mouse model of sitosterolemia. $\mathrm{J}$ Biol Chem 283:6281-6287

8. Miettinen TA (1980) Phytosterolaemia, xanthomatosis and premature atherosclerotic arterial disease: A case with high plant sterol absorption, impaired sterol elimination and low cholesterol synthesis. Eur J Clin Investig 10:27-35

9. Lutjohann D (2006) Cholesterol metabolism in the brain: Importance of 24S-hydroxylation. Acta Neurol Scand Suppl 185:33-42

10. Tint GS, Seller M, Hughes-Benzie R, Batta AK, Shefer S, Genest D, Irons M, Elias E, Salen G (1995) Markedly increased tissue 
concentrations of 7-dehydrocholesterol combined with low levels of cholesterol are characteristic of the Smith-Lemli-Opitz syndrome. J Lipid Res 36:89-95

11. Plat J, Nichols JA, Mensink RP (2005) Plant sterols and stanols: effects on mixed micellar composition and LXR (target gene) activation. J Lipid Res 46:2468-2476

12. Mulder M, Jansen PJ, Janssen BJ, van de Berg WD, van der Boom H, Havekes LM, de Kloet RE, Ramaekers FC, Blokland A (2004) Low-density lipoprotein receptor-knockout mice display impaired spatial memory associated with a decreased synaptic density in the hippocampus. Neurobiol Dis 16:212-219

13. Vanmierlo T, Rutten K, Dederen J, Bloks VW, van Vark-van der Zee LC, Kuipers F, Kiliaan A, Blokland A, Sijbrands EJ, Steinbusch H, Prickaerts J, Lutjohann D, Mulder M (2009) Liver $\mathrm{X}$ receptor activation restores memory in aged $\mathrm{AD}$ mice without reducing amyloid. Neurobiol Aging, Aug 102009 [Epub ahead of print]

14. Papakostas GI, Ongur D, Iosifescu DV, Mischoulon D, Fava M (2004) Cholesterol in mood and anxiety disorders: review of the literature and new hypotheses. Eur Neuropsychopharmacol 14:135-142

15. Kaplan JR, Shively CA, Fontenot MB, Morgan TM, Howell SM, Manuck SB, Muldoon MF, Mann JJ (1994) Demonstration of an association among dietary cholesterol, central serotonergic activity, and social behavior in monkeys. Psychosom Med 56:479-484

16. Scanlon SM, Williams DC, Schloss P (2001) Membrane cholesterol modulates serotonin transporter activity. Biochem Mosc 40:10507-10513

17. Plösch T, Bloks VW, Terasawa Y, Berdy S, Siegler K, Van Der Sluijs F, Kema IP, Groen AK, Shan B, Kuipers F, Schwarz M (2004) Sitosterolemia in ABC-transporter G5-deficient mice is aggravated on activation of the liver-X receptor. Gastroenterology 126:290-300

18. Rutten K, Vente JD, Sik A, Ittersum MM, Prickaerts J, Blokland A (2005) The selective PDE5 inhibitor, sildenafil, improves object memory in Swiss mice and increases cGMP levels in hippocampal slices. Behav Brain Res 164:11-16

19. Sik A, van Nieuwehuyzen P, Prickaerts J, Blokland A (2003) Performance of different mouse strains in an object recognition task. Behav Brain Res 147:49-54

20. Mulder M, Blokland A, van den Berg DJ, Schulten H, Bakker AH, Terwel D, Honig W, de Kloet ER, Havekes LM, Steinbusch HW, de Lange EC (2001) Apolipoprotein E protects against neuropathology induced by a high-fat diet and maintains the integrity of the blood-brain barrier during aging. Lab Invest 81:953-960

21. Shepherd JK, Grewal SS, Fletcher A, Bill DJ, Dourish CT (1994) Behavioural and pharmacological characterisation of the elevated "zero-maze" as an animal model of anxiety. Psychopharmacol Berl 116:56-64

22. van Donkelaar EL, Blokland A, Lieben CK, Kenis G, Ferrington L, Kelly PA, Steinbusch HW, Prickaerts J (2010) Acute tryptophan depletion in C57BL/6 mice does not induce central serotonin reduction or affective behavioural changes. Neurochem Int 56:21-34

23. Cryan JF, Mombereau C, Vassout A (2005) The tail suspension test as a model for assessing antidepressant activity: Review of pharmacological and genetic studies in mice. Neurosci Biobehav Rev 29:571-625

24. Steru L, Chermat R, Thierry B, Mico JA, Lenegre A, Steru M, Simon P, Porsolt RD (1987) The automated Tail Suspension Test: A computerized device which differentiates psychotropic drugs. Prog Neuropsychopharmacol Biol Psychiatry 11:659-671

25. Lutjohann D, Brzezinka A, Barth E, Abramowski D, Staufenbiel $\mathrm{M}$, von Bergmann $\mathrm{K}$, Beyreuther $\mathrm{K}$, Multhaup G, Bayer TA (2002) Profile of cholesterol-related sterols in aged amyloid precursor protein transgenic mouse brain. J Lipid Res 43:10781085

26. Zambon D, Quintana M, Mata P, Alonso R, Benavent J, CruzSanchez F, Gich J, Pocovi M, Civeira F, Capurro S, Bachman D, Sambamurti K, Nicholas J, Pappolla MA (2010) Higher incidence of mild cognitive impairment in familial hypercholesterolemia. Am J Med 123:267-274

27. Schiepers OJ, de Groot RH, van Boxtel MP, Jolles J, de Jong A, Lutjohann D, Plat J, Mensink RP (2009) Consuming functional foods enriched with plant sterol or stanol esters for 85 weeks does not affect neurocognitive functioning or mood in statin-treated hypercholesterolemic individuals. J Nutr 139:1368-1373

28. Bernick C, Katz R, Smith NL, Rapp S, Bhadelia R, Carlson M, Kuller L (2005) Statins and cognitive function in the elderly: The Cardiovascular Health Study. Neurology 65:1388-1394

29. Evans MA, Golomb BA (2009) Statin-associated adverse cognitive effects: Survey results from 171 patients. Pharmacotherapy 29:800-811

30. Teunissen CE, De Vente J, von Bergmann $\mathrm{K}$, Bosma $\mathrm{H}$, van Boxtel MP, De Bruijn C, Jolles J, Steinbusch HW, Lutjohann D (2003) Serum cholesterol, precursors and metabolites and cognitive performance in an aging population. Neurobiol Aging $24: 147-155$

31. Salen G, Horak I, Rothkopf M, Cohen JL, Speck J, Tint GS, Shore V, Dayal B, Chen T, Shefer S (1985) Lethal atherosclerosis associated with abnormal plasma and tissue sterol composition in sitosterolemia with xanthomatosis. J Lipid Res 26:1126-1133

32. Al-Yousuf MH, Ali BH, Bashir AK, Tanira MO, Blunden G (2002) Central nervous system activity of Leucas inflata Benth. in mice. Phytomedicine 9:501-507

33. Iivonen H, Nurminen L, Harri M, Tanila H, Puolivali J (2003) Hypothermia in mice tested in Morris water maze. Behav Brain Res 141:207-213

34. Aguirre-Hernandez E, Rosas-Acevedo H, Soto-Hernandez M, Martinez AL, Moreno J, Gonzalez-Trujano ME (2007) Bioactivity-guided isolation of beta-sitosterol and some fatty acids as active compounds in the anxiolytic and sedative effects of Tilia americana var. mexicana. Planta Med 73:1148-1155 